SFB

Markups and fiscal

823

transmission in a panel of

OECD countries

Falko Juessen, Ludger Linnemann

Nr. 23/2010
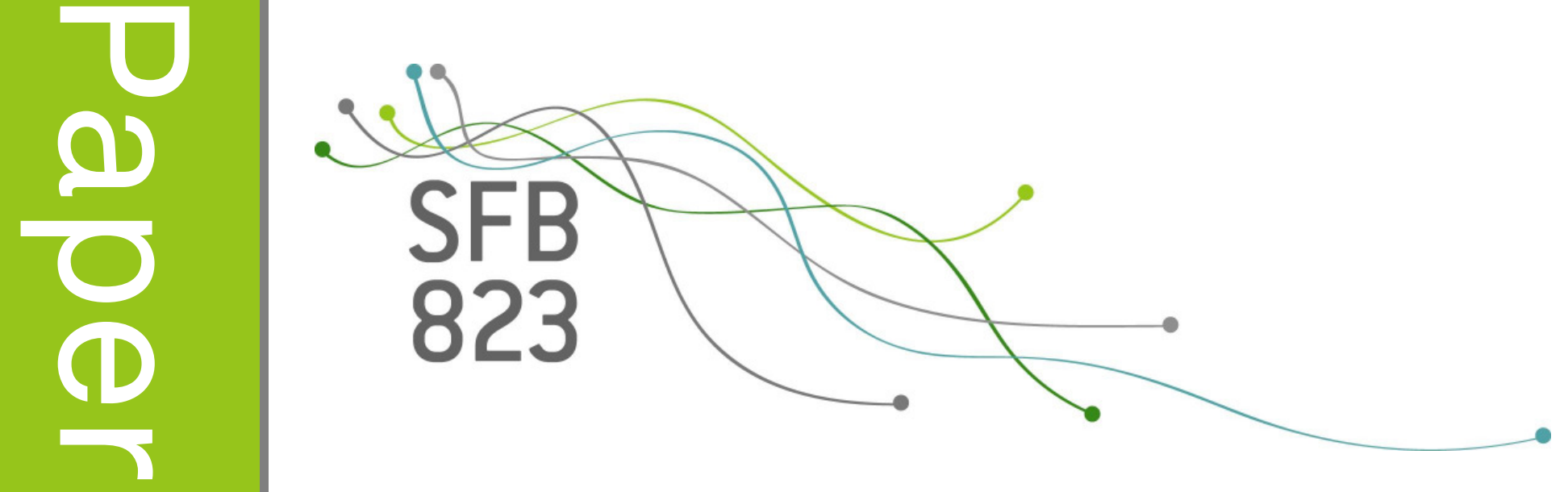



\title{
Markups and fiscal transmission in a panel of OECD countries
}

\author{
Falko Juessen ${ }^{1}$ \\ TU Dortmund University and IZA
}

Ludger Linnemann ${ }^{2,3}$

TU Dortmund University

This version: May 6, 2010

\begin{abstract}
This paper studies the role of the markup of price over marginal cost for the transmission of fiscal policy shocks. We construct time series of markups allowing for fluctuations in capacity utilization and total factor productivity and use an aggregate production function that is more general than Cobb-Douglas. Including the constructed markup series in a panel vector autoregression with annual OECD data, we find that a positive shock to government spending substantially lowers markups while raising output, consumption, real interest rates, and government debt. The positive output response appears to result mainly from the positive reaction of capital utilization rather than from the one of hours worked.
\end{abstract}

JEL classification: E62, E32, C33

Keywords: Fiscal policy; Government spending; Markups; Panel VAR

\footnotetext{
${ }^{1}$ TU Dortmund University, Department of Economics, Vogelpothsweg 87, D-44221 Dortmund, Germany, email: falko.juessen@tu-dortmund, tel: +49/231/7553291.

${ }^{2}$ Corresponding author. TU Dortmund University, Department of Economics, Vogelpothsweg 87, D44221 Dortmund, Germany, email: ludger.linnemann@tu-dortmund, tel: +49/231/7553102.

${ }^{3}$ Financial support by the Deutsche Forschungsgemeinschaft (SFB 823, 'Statistical modelling of nonlinear dynamic processes') is gratefully acknowledged.
} 


\section{Introduction}

This paper empirically studies the role of the markup of price over marginal cost in the macroeconomic transmission of shocks to real government spending for a panel of OECD countries. Current macroeconomic policy debates have brought the question of the empirical effects of government spending to the forefront of attention. One aspect is the recent debate about the existence and size of the fiscal multiplier on private spending (e.g. Barro and Redlick, 2009, Hall, 2009), which is of obvious importance for the question whether a fiscal stimulus is effective in moving the economy out of recession. A large literature starting with Blanchard and Perotti (2002) has attempted to estimate the effects of shocks to government spending on output and other variables from identified vector autoregressions (see Perotti, 2007 for a survey). Apart from the size of the fiscal output multiplier, the impact of fiscal shocks on other variables has received considerable attention, in particular private consumption, real interest rates and real wages, since the responses of these variables may shed light on the empirical relevance of different theories of fiscal policy transmission.

Recent studies have investigated the precise nature of the empirical transmission mechanism of government spending shocks. In particular, several authors have pointed at the importance of the markup of price over marginal cost for understanding the effects of fiscal shocks. Hall (2009) argues that Keynesian features of fiscal policy transmission, i.e. a large positive output multiplier and positive responses of private consumption and real wages to increased government spending, rely on a negative relation of the markup of price over marginal cost to the level of activity. The intuition is that only when the price-marginal cost markup decreases in reaction to higher government spending, the resulting increase in labor supply can materialize without a strong reduction in the real wage, or even with a moderate real wage increase. Therefore, with a markup that is countercyclical conditional on government spending shocks, there can be sizeable output multipliers of fiscal spending that need not be accompanied by strong decreases in real wages or consumption, much as the empirical evidence suggests. The same point is made by Bilbiie (2009).

In general, a countercyclical markup ratio is a feature of New Keynesian models with sticky prices, but could also be implied by models with flexible prices when the desired markup changes in response to a shock. A model which assigns a central role to markups for fiscal policy transmission has been presented by Ravn et al. (2007). In their setup, the deep habits property of demand implies that a shock that leads to a positive output response increases the importance of the non-price elastic component of demand, such that the overall demand elasticity rises and the optimal markup desired by firms declines. Ravn 
et al. (2007) show that their model can explain empirically observed transmission effects of fiscal shocks if the markup that is implied by their estimated model declines sufficiently. However, they also note that 'a natural question is whether in the data markups of prices over marginal cost indeed fall in response to a positive innovation in government spending, as required for our theoretical model to capture the observed increase in consumption and real depreciation of the exchange rate. To our knowledge, there is no available SVAR evidence documenting the response of markups to government spending shocks' (Ravn et al., 2007, p. 23; our emphasis).

Such direct evidence has since been presented by Monacelli and Perotti (2008), but only for the US and, more importantly, based on the assumption that production is CobbDouglas and that there is no endogenous cyclical utilization of production factors, such that the markup is directly observable from the inverse of labor's share in output. This is similar to the construction of real marginal costs (the inverse of the markup) in Gali and Gertler (1999). Monacelli and Perotti (2008) find that in a VAR on aggregate US data their markup measure - i.e. the inverse of the labor share - indeed declines following a fiscal spending shock.

The central contribution of the present paper is that we construct direct measures of the price marginal cost markups that do not rely on the Cobb-Douglas assumption and allow for variable capacity utilization. We use first order conditions from a standard optimizing business cycle model to construct time series of markup measures and include them as variables in a panel VAR model estimated using annual data for 19 OECD countries ranging from 1970 to 2008. Generalizing the production function seems important, as there is empirical evidence that the elasticity of substitution between labor and capital is typically lower than one (see e.g. Antras, 2004, who presents evidence for the US, or Chirinko, 2008). While allowing for a more general production technology is an obvious advantage, the downside is that if production is not Cobb-Douglas the identification of the markup ratio requires an estimate of the technology process. In principle, this could be achieved using a measure of total factor productivity (the Solow residual). However, the standard Solow residual is known to be biased in the case of monopolistic competition (Hall, 1991) and contaminated by unobserved fluctuations in the degree of capacity utilization. Increased utilization could erroneously be taken for an increase in total factor productivity due to improved technology, and thus for an increase in the markup. One therefore has to control for unobservable utilization.

To address this issue, we construct empirical measures jointly identifying the time series of the markup, capacity utilization, and total factor productivity. The method is similar to Rotemberg and Woodford $(1991,1999)$ and Basu et al. (2006), but while the 
latter authors use regression techniques to estimate a constant markup ratio, we follow the former and use a calibration procedure that delivers the whole time series of the markup. Our approach for controlling for utilization changes and their effect on measured technology change and the markup is similar to Imbs (1999) in that we use the first order conditions of a standard model in which the utilization of capital is a choice variable, as in Greenwood et al. (1988) and a large subsequent literature. Other approaches to control for cyclical utilization have been proposed by Basu (1996) by using materials input and by Burnside et al. (1995) by using energy input as a proxy for utilization. Our method provides a theoretically well-founded alternative that does not require access to data on materials and energy use which is rarely available in a cross-country context.

The largest part of the previous literature on fiscal policy transmission uses data for the US or a small number of additional countries like Canada, the UK, and Australia (see Perotti, 2005, 2007, Ravn et al., 2007, Pappa, 2009; an exception is Beetsma et al., 2008, who use annual data to study the international transmission of fiscal shocks via trade balances). The main reason for this choice is data availability, since quarterly time series of sufficient length for fiscal variables are rarely available. In this paper, we use annual data for OECD countries and estimate the effects of fiscal shocks by using panel VAR techniques. Using annual data has an obvious drawback concerning identification. The standard assumption in the fiscal VAR literature (e.g. Perotti, 2007) is that government spending can be ordered first in a recursive identification. This is plausible with quarterly or higher frequency data, as lags in the planning and implementation of fiscal policy decisions can plausibly be assumed to rule out any endogenous reaction of government spending to the state of the business cycle within a quarter (the situation is more complicated when identification of tax shocks is aimed at, which is not the case here). However, with annual data this line of reasoning is arguably less compelling, as fiscal policy might well be changed during a year in response to other shocks. Perotti (2007) points out that this may entail a negative bias in the estimated responses of output and private consumption to fiscal shocks. In response to an adverse business cycle shock, governments may increase spending within the year to act countercyclically, which would mistakenly be interpreted as an instance of negative output reactions to fiscal shocks by a recursive VAR. Unfortunately, it is not clear whether governments typically adjust spending in a countercyclical fashion, such that the direction of the possible bias is hard to predict. More generally, however, Beetsma et al. (2010) argue that the bias in using a recursive VAR with government spending ordered first may well be negligible. These authors study the possible identification problem by comparing VARs on annual and quarterly data where both frequencies are available. They find that the assumption of a zero response of government spending to output within a 
year is not rejected by the data. Therefore, they conclude that the recursive identification is a sensible procedure even with annual data. The interpretation is that the budget is set once a year and the variations within the year are comparatively small. Our empirical identification approach uses this argument.

Using annual data has several advantages (beyond data availability). Favero and Giavazzi (2007) argue that fiscal VARs are biased as long as the level of debt (in relation to output), which is crucial for the long term fiscal sustainability, is not included. However, data on government debt is usually only available over longer samples at annual frequencies. Using annual data allows us to respond to Favero and Giavazzi's (2007) argument by including the debt to output ratio as a variable in our panel VARs.

The main results are as follows. We find that markups do tend to decline following a positive fiscal spending shock, although to a limited amount. Interestingly, the estimated amount of markup reduction due to government spending shocks is remarkably close to the theoretically implied size of markup reduction that Ravn et al. (2007) have to postulate in order to be able to explain the empirical transmission mechanism of fiscal shock within their model of variable markups due to deep habits. We point out that while the estimated markup reaction quantitatively depends on calibrated parameters, the sign of the response is robust for a broad range of parameters that spans virtually all practically relevant parameter sets. In particular, the markup reacts most strongly negatively to a positive government spending shock if the elasticity of substitution between effective capital input and labor in production is close to one, and if utilization does not vary strongly. This is the setting used by Monacelli and Perotti (2008) who assume a Cobb-Douglas production function and neglect changes in capacity utilization. Their work is thus, in the light of our results, likely to overstate the countercyclical markup response to fiscal shocks. However, there is still a sizeable and theoretically important estimated markup reduction even in the case of our preferred specification of limited short-run capital-labor substitutability and more highly variable capacity utilization.

We further establish that changes in capacity utilization seem to be a major channel of adjustment following fiscal shocks. While the estimated responses of output and private consumption are positive and quantitatively in line with previous studies, we also find that the estimated response of hours worked is weak and barely positive. This makes it difficult to explain the sizeable output response through the standard wealth effect on labor supply that is operative in conventional models. The positive output reaction is initially several times stronger than the response of hours, which seems puzzling given decreasing returns to labor. However, we show that variable capacity utilization seems to go a long way toward explaining this apparent contradiction, since utilization reacts strongly positively 
on impact.

The remainder is organized as follows. Section 2 briefly describes the data set used, with a more detailed discussion deferred to the appendix, and outlines the empirical strategy. Section 3 presents the construction of the markup and utilization series used in the subsequent estimates. Section 4 presents empirical results and section 5 concludes.

\section{Data and econometric approach}

We estimate panel VARs using annual data for 19 OECD countries for the period 1970 to 2008. The source of data is mostly the European Commission's AMECO database, while interest rate data are from the IMF's International Financial Statistics and hours worked (which are needed in the markup calculations) are from the Groningen Growth and Development Centre. The data is measured at the aggregate level of each country; the countries included are those OECD members for which the data are available over the whole time span of the sample period; see the appendix for details.

We employ both directly observable and constructed variables. The baseline set of variables consists of real (deflated with the gdp price index) government consumption spending per head of population $g_{t}$, real gdp per head of population $y_{t}$, real private consumption expenditures per head of population $c_{t}$, a real interest rate $R_{t}$ (constructed as the nominal interest rate on long-term government bonds less the rate of change in the gdp deflator), and the government debt-to-output ratio $d_{t}$ (constructed as the general government's consolidated gross debt as a percentage of gdp at market prices). The VARs are identified recursively with government spending ordered first. This reflects the common assumption (Blanchard and Perotti, 2002, Perotti, 2007) that government spending does not react endogenously to the state of the economy within the period, but only with a lag. While this assumption is rarely debated in the context of VARs using quarterly data, it is less uncontroversial when annual data is used. However, Beetsma et al. (2010) report evidence for cases where both quarterly and annual data are available that the bias entailed by assuming government spending to be exogenous within the year might well be negligible.

Additionally, we use the price marginal cost markup $\mu_{t}$, and the rate of capacity utilization $u_{t}$, which are unobservable in principle but can be constructed to follow from optimizing first order conditions through a calibration approach based on Rotemberg and Woodford $(1991,1999)$ in a way discussed in detail in the next section. Furthermore, some of the specifications also make use of total hours worked $h_{t}$.

To control for cross-country unobserved heterogeneity, the panel VARs include country 
fixed effects. Moreover, all estimations discussed in this paper control for time effects. For dynamic panel data models, it is well-known that the simple fixed effects estimator is not consistent for a finite time dimension, see Nickell (1981). Since the associated bias decreases in the number of time periods, a practical question is whether the number of time periods available in our study $(T=39)$ is sufficiently large to make the bias neglible. In Juessen and Linnemann (2010), we have compared the perfomance of various estimation techniques for panel VARs estimated from macro data. We find that, for datasets having similar dimensions as the one used in the present study, the bias of the simple fixed effects estimator can still be substantial (also see Judson and Owen 1998 for related singleequation evidence). In Juessen and Linnemann (2010) we suggest that bias-corrected versions of the fixed effects estimator are the estimators of choice when estimating panel VARs from macro data. Specifically, we show that the Hahn and Kuersteiner (2002) biascorrected fixed effects estimator yields almost unbiased estimates. Accordingly, we use this estimation technique for the present estimation problem. For the sake of completeness, we will present a comparison of results (see appendix A.4) obtained using the simple fixed effects estimator and our preferred estimation technique, the Hahn and Kuersteiner (2002) estimator.

To make the Hahn and Kuersteiner (2002) estimator suitable for models with higher order VAR dynamics (we use two lags), one can use the fact that any $\operatorname{VAR}(p)$ process can be written in VAR(1) form by imposing blockwise zero and identity restrictions on the VAR slope coefficients, see e.g. Lütkepohl (2006, p. 15 and p. 194) and also Hahn and Kuersteiner (2002, p. 1640). We therefore use an extended version of the Hahn and Kuersteiner (2002) estimator that allows for linear constraints. To control for time effects, we use a projection matrix to average the observations over individuals and then use the transformed data in the estimations (which is equivalent to including the matrix of time dummies as regressors). Finally, as in Beetsma, Giuliodori, and Klaassen (2006, 2008), we control for linear country-specific time trends.

\section{Markup construction}

The approach used to construct time series of the price marginal cost markup $\mu_{t}$ and the rate of capital utilization $u_{t}$ is based on Rotemberg and Woodford $(1991,1999)$. The approach is also similar to Basu et al. (2006), but the difference is that these authors estimate a constant markup as a regression parameter, while we identify a time series of variable markup ratios based on postulating specific values for some structural model parameters. To construct series for the markup, we use a standard optimizing business 
cycle model with monopolistic competition and endogenous utilization of capital (similar to e.g. Christiano et al., 2005, or Justiniano et al., 2009). Note that only the static intratemporal first order conditions of the model are needed for the procedure to construct markups and utilization rates. This is clearly an advantage, since the most controversial aspects of macroeconomic models pertain to the intertemporal optimality conditions, like consumption Euler equations. These are not needed here at all, such that the proposed empirical strategy would be valid not only in the specific simple model used here, but also in a wider class of models which might differ greatly with respect to their predictions concerning dynamics. Note that we also do not make use of optimizing conditions with respect to labor supply, which are also highly controversial; our method should thus be robustly valid in many labor market models.

Households have a concave period utility function $v\left(c_{t}, n_{t}\right)$, where $c_{t}$ is private consumption and $n_{t}$ is labor supply (hours), and maximize

$$
E_{0} \sum_{t=0}^{\infty} \beta^{t} v\left(c_{t}, n_{t}\right), \quad \beta \in(0,1),
$$

subject to the flow budget constraint

$$
w_{t} n_{t}+r_{t} u_{t} k_{t}+\kappa_{t}=c_{t}+i_{t}+a\left(u_{t}\right) k_{t}
$$

where $w_{t}$ and $r_{t}$ are the real wage and capital rental rates, respectively, $k_{t}$ is the capital stock, $\kappa_{t}$ is residual firm profits, and $i_{t}$ is investment. The variable $u_{t}>0$ is the endogenous degree of utilization of capital and the function $a\left(u_{t}\right)$ determines the resource costs of utilization per unit of capital (a specification widely used in the literature, e.g. Christiano et al. 2005, Justiniano et al. 2009). It is assumed that

$$
a\left(u_{t}\right)=\frac{\chi}{1+\psi} u_{t}^{1+\psi}, \quad \chi, \psi>0
$$

Here, $\psi=\delta^{\prime \prime} u / \delta^{\prime}$ measures the costliness of varying utilization; it is thus an inverse index of the variability of utilization in equilibrium. The capital accumulation constraint is given by

$$
k_{t+1}=(1-\delta) k_{t}+i_{t},
$$

where $\delta \in(0,1)$ is the constant depreciation rate. ${ }^{1}$

\footnotetext{
${ }^{1}$ We also experimented with a more general version where labor effort is variable and total labor input $n_{t}$ is decomposed as $n_{t}=m_{t} h_{t} e_{t}$ with $m_{t}$ employment, $h_{t}$ per capita hours, and $e_{t}$ labor effort. As in Basu et al. (2006), then, under certain conditions labor effort can be shown (from the household's first order conditions) to be uniquely related to per capita hours. The results of these experiments showed that robustly (i.e. for all parameters that govern the relationship between per capita hours and effort that we
} 
The household first order conditions for $n_{t}, c_{t}$, and $u_{t}$ are (letting subindices denote partial derivatives)

$$
\begin{aligned}
w_{t} & =-u_{n t} / u_{c t}, \\
u_{c t} & =\beta E_{t} u_{c t+1}\left[r_{t+1} u_{t+1}+1-\delta-a\left(u_{t+1}\right)\right], \\
r_{t} k_{t} & =a^{\prime}\left(u_{t}\right) k_{t}=\chi u_{t}^{\psi} k_{t} .
\end{aligned}
$$

The firm sector is characterized by a continuum of firms indexed on $i \in[0,1]$ each producing a variety of the output good and engaged in monopolistic competition. The $i$-th firm's demand is assumed to be

$$
y_{i t}=p_{i t}^{-\varepsilon_{t}} y_{t}
$$

where $y_{i t}$ is individual output, $y_{t}$ is aggregate output, $p_{i t}$ is the relative price of the $i$-th good in terms of the general price level, and $\varepsilon_{t}>1$ is the possibly time-varying absolute value of the elasticity of demand. The technology is

$$
y_{i t}=z_{t} F\left(u_{i t} k_{i t}, n_{i t}\right),
$$

where $F($.$) is a production function with the usual neoclassical properties and z_{t}$ is the level of technology. We assume constant returns to scale of the function $F($.) in its two arguments $u_{i t} k_{i t}$ and $n_{i t}$. The firm chooses employment $n_{i t}$ and utilized capital $u_{i t} k_{i t}$ to maximize profits, taking aggregate output, technology, and real factor prices as given. Introducing the markup

$$
\mu_{t}=\frac{\varepsilon_{t}}{\varepsilon_{t}-1},
$$

we can write the first order conditions that describe a symmetric equilibrium (in which each firm chooses the same factor inputs and charges the same price, such that the individual firm index can be dropped) as

$$
\begin{aligned}
& z_{t} F_{2}=\mu_{t} w_{t}, \\
& z_{t} F_{1}=\mu_{t} r_{t},
\end{aligned}
$$

where $F_{1} \equiv \partial F\left(u_{i t} k_{i t}, n_{i t}\right) / \partial\left(u_{i t} k_{i t}\right)$ and $F_{2} \equiv \partial F\left(u_{i t} k_{i t}, n_{i t}\right) / \partial\left(n_{i t}\right)$.

Now consider the equilibrium conditions (3), where we can substitute out the difficult

tried) the response of per capita hours to government spending shocks is rather flat. This also implies that labor effort does not contribute significantly to the responses. We therefore proceed with the simpler version where labor input is measured in terms of hours and there is no variable effort. 
to observe rental rate of capital through (6), (5), and the symmetric version of (4) which reads $y_{t}=z_{t} F\left(u_{t} k_{t}, n_{t}\right)$. These are three equations in the eight endogenous variables $k_{t}, u_{t}, \mu_{t}, n_{t}, y_{t}, w_{t}, z_{t}$. Our strategy is to treat $n_{t}, k_{t}, y_{t}, w_{t}$ as observable variables and to use data on these as well as the information embodied in the aforementioned equilibrium conditions to empirically determine implied time paths of the unobservable variables $\mu_{t}, z_{t}, u_{t}$

We do so via a log-linear approximation along a balanced growth path; the appendix gives the details of the calculations. Denote for any variable $x_{t}$ its constant value on the balanced growth path by a variable without time subscript, $x$, and the log-deviation as $\widehat{x}_{t}=\ln \left(x_{t} / x\right)$. The log-deviations of the markup, utilization, and technology can then be recovered as (see appendix)

$$
\left(\begin{array}{c}
\widehat{u}_{t} \\
\widehat{\mu}_{t} \\
\widehat{z}_{t}
\end{array}\right)=\left(\begin{array}{ccc}
-\frac{\mu s_{K}}{\sigma} & 1 & -1 \\
\frac{\mu s_{L}}{\sigma}+\psi & 1 & -1 \\
\mu s_{K} & 0 & 1
\end{array}\right) \quad\left(\begin{array}{cccc}
0 & -\frac{\mu s_{K}}{\sigma} & \frac{\mu s_{K}}{\sigma} & -1 \\
0 & \frac{\mu s_{L}}{\sigma} & -\frac{\mu s_{L}}{\sigma} & 0 \\
1 & -\mu s_{L} & -\mu s_{K} & 0
\end{array}\right)\left(\begin{array}{c}
\widehat{y}_{t} \\
\widehat{n}_{t} \\
\widehat{k}_{t} \\
\widehat{w}_{t}
\end{array}\right)
$$

where $s_{K}$ and $s_{L}$ are the shares of capital and labor along the balanced growth path and $\sigma$ is the elasticity of substitution between capital and labor in the production function. For the empirical work, we thus need $\widehat{y}_{t}, \widehat{n}_{t}, \widehat{k}_{t}, \widehat{w}_{t}$, which we calculate as log-deviations from deterministic linear trends (using quadratic time trends did not change the results much). Further, we need a choice of constants for the steady state parameters $\mu, \sigma, \psi$, and $s_{L}$ (whence $s_{K}=\left(1-\mu s_{L}\right) / \mu$ follows from constant returns to scale). This enables us to find the time path of the deviations $\widehat{u}_{t}, \widehat{\mu}_{t}, \widehat{z}_{t}$ from which the levels can be recovered, e.g. $\mu_{t}=\exp \left(\widehat{\mu}_{t}\right) \cdot \mu$, once constant steady state levels for $u, \mu, z$ are given.

We apply this procedure for each country in the data set separately, such that we get time series $\mu_{t}, u_{t}, z_{t}$ for each individual country. Since information on empirically realistic calibration values for the constant parameters is scarce for countries other than the US, we choose the same parameter set for all countries. For the average markup $\mu$, we use the value 1.2 which is commonly used in the business cycle literature based on results by Basu and Fernald (1996) for the US. The labor income share is set to the customary value $s_{L}=2 / 3$. The crucial parameters that remain are the elasticity of capital-labor substitution $\sigma$ and the elasticity of the depreciation cost with respect to utilization $\psi$. In most studies, such as Monacelli and Perotti (2008) or Basu et al. (2006), a Cobb-Douglas assumption implicitly restricts $\sigma$ to one. One of the main advantages of the procedure followed here is that we can relax this restrictive assumption. Antras (2004) finds that, for the US, the typical elasticity of capital-labor substitution lies between 0.6 and 0.9 , while a 
part of his various estimates suggest that it could even be well below 0.5. Chirinko (2008) surveys the literature estimating the elasticity of substitution between capital and labor and concludes that the elasticity is in the range of 0.4 to 0.6 and that, consequently, 'there is little evidence to sustain the assumption of a Cobb-Douglas production function'. We thus choose $\sigma=0.5$ as our benchmark value and report the sensitivity of the estimates when the markup series is constructed using other values for $\sigma$.

The parameter $\psi$ is even more difficult to pin down empirically. Note that in the limit if $\psi$ gets large, the model collapses to one without a utilization margin, whereas a low value of $\psi$ implies low costs of varying capital utilization, such that measured utilization would be highly variable over the business cycle. The latter is indeed found by studies which estimate this parameter in the context of full scale empirical DSGE models, e.g. Christiano et al. (2005). Baxter and Farr (2005) use a baseline value of 1, based on estimates in Basu and Kimball (1997), but also note that these authors report very wide confidence intervals that do not rule out infinitesimally small values of $\psi$. Jaimovich and Rebelo (2009) use $\psi=0.15$, but also point out that existing literature gives little guidance in this choice and hence conduct a sensitivity analysis. Given the uncertainty surrounding the choice of this parameter, we (somewhat arbitrarily) choose $\psi=1$ as a benchmark, and report a sensitivity analysis of the VAR results for the case of highly variable utilization $(\psi=0.01)$ as well as almost constant utilization $(\psi=10)$. The steady state values of utilization $u_{t}$ and of technology $z_{t}$ are normalized to one without loss of generality.

Figures 5 and 6 (see appendix A.3) display the markup series constructed in this way for the benchmark parameter set with $\sigma=0.5$ and $\psi=1$ for all 19 countries in the data set. Note that while the level of the average markup is imposed a priori, the fluctuations visible in the figures are not. As a preliminary step, we can thus use our estimates to comment on the long standing question whether markups are (unconditionally) countercyclical over the business cycle (see Rotemberg and Woodford, 1992, 1999, Hall, 2009). In our sample, the median correlation of the markup series with linearly detrended output is -0.28 ; in 7 out of the 19 country cases we find a weakly procyclical behavior of the markup. The countercyclicality of the markup becomes somewhat weaker if we choose the scenario of high variability in capital utilization $(\psi=0.01)$, where the median correlation between the markup and detrended output drops to -0.21 . In the case of low variability in capital utilization $(\psi=10)$ the median correlation is -0.27 . Thus, we conclude that some modestly countercyclical markup behavior seems to be present in our sample.

However, the question whether the markup is unconditionally countercyclical is arguably less important in our context than its conditional correlation with output in response to fiscal shocks. Thus, in the next section, we proceed by using the markup series as 
variables in a fiscal VAR to shed light on the conditional variation in markups in the presence of government spending shocks, and thus on their role in the transmission mechanism of fiscal policy.

\section{Results}

\subsection{Baseline panel VAR}

The baseline panel VAR consists of real per capita government spending $g_{t}$, real per capita gdp $y_{t}$, real per capita private consumption $c_{t}$, the markup series constructed above $\mu_{t}$, the ex-post real interest rate (deflated with the gdp price index log-change) on long-term government bonds $R_{t}$, and the ratio of government debt to gdp $d_{t}$; more detailed data definitions can be found in the appendix. As the construction of the markup ratio uses a loglinearization procedure, we allow for country-specific differences in the balanced growth paths by entering the variables in the form of log-deviations from linear trends (though it should be noted that all results reported below are robust to using the log-levels of the variables). Throughout, we set up the panel VARs with two lags of each endogenous variable, and include country fixed effects as well as a matrix of time dummy variables. Note that alternatively using either only one lag, or three lags, of the endogenous variables did not change the results by much. Identification relies on ordering government spending first for the Cholesky decomposition that delivers the structural fiscal policy shock, as customary in the the empirical literature (e.g. Perotti, 2007); see the introduction for a discussion of this standard approach in the current context.

Figure 1 shows impulse responses to a one percent shock to government spending in the baseline panel VAR (with $90 \%$ bootstrapped confidence bands). The panel VAR is estimated using the bias-corrected fixed effects estimator developed by Hahn and Kuersteiner (2002). For the sake of completeness, appendix A.4 presents the corresponding results obtained using the standard fixed effects estimator. This estimator is known to have a negative bias (see Juessen and Linnemann, 2010). In the present context, the impulse responses from simple fixed effects estimates are still reasonably close to the bias-corrected ones, but the responses are more short-lived than under bias correction.

The figure shows that fiscal shocks tend to raise government spending rather persistently, as commonly found in the literature. There is a significantly positive impact response of real gdp and a slightly weaker positive reaction of private consumption. Again, this result is to be expected from previous studies. The size of the 'fiscal multplier' on output is similar to what has been reported elsewhere: the impact effect of a one percent shock to government spending is to raise gdp by about 0.11 percent, which - evaluated 


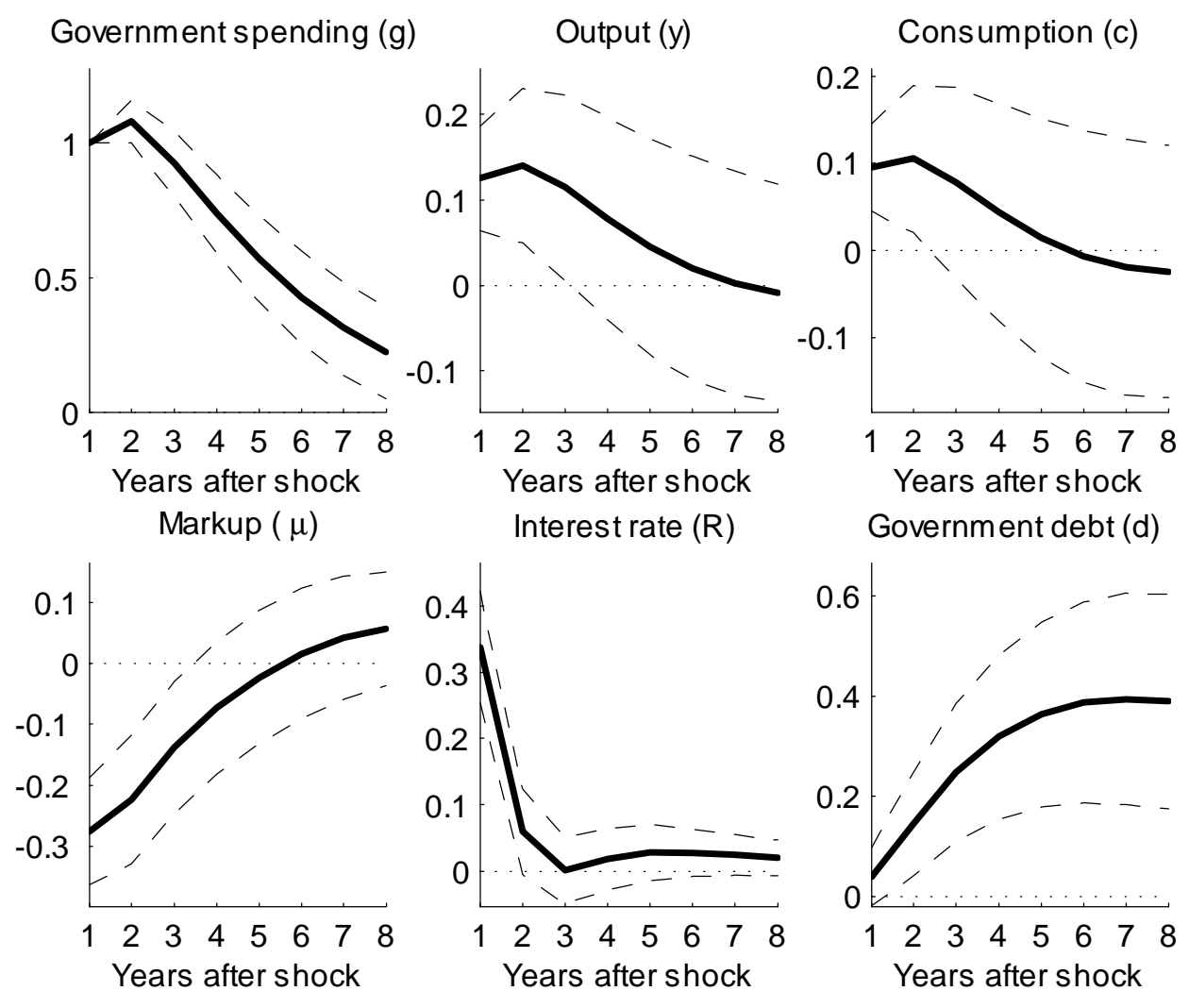

Figure 1: Impulse responses to a one percent shock to government spending

at the sample mean ratio of government spending to output of 0.19 - translates into an increase of 0.58 units of gdp per unit increase in government spending. This is very close to the corresponding value of 0.52 found by Ravn et al. (2007) in their four country panel VAR with quarterly data for Australia, Canada, the UK and the US. An output multiplier of around 0.5 is also found by Hall (2009) for the US using only military government spending (as the arguably most exogenous component of total government spending) as the impulse variable.

The debt to output ratio increases strongly and very persistently following a surge in government spending. This can be viewed as saying that government spending is typically deficit financed in the short run. However, over time the budget is adjusted in order to keep the build-up of debt under control, such that the debt to output ratio shows some mean reversion over the longer run. Note that Favero and Giavazzi (2007) argue that fiscal VARs are biased if no measure of debt is included, since the estimation of the adjustment process should allow for the interactions induced by the presence of the government budget constrained. Thus, including debt to output ratios can be seen as a way to avoid these problems (though leaving out the debt ratio does not change any of the other results 
fundamentally).

Moreover, figure 1 shows a marked but short-lived increase in the real bond interest rate. This is in contrast to some of the previous literature, which typically finds weak reactions of interest rates to fiscal shocks (e.g. Corsetti and Müller, 2006). The reason could be due to differences in the empirical measures of interest rates used and in the extended country sample analyzed here. If we include the nominal government bond interest rate and the gdp inflation rate separately in the VAR (instead of using a real interest rate measure), we get an almost flat response of the nominal interest rate and a decrease in inflation in response to a government spending shock. However, the responses of the other variables are not much affected by the choice of the interest rate measure, such that these empirical choices do not turn out to be crucial for the results that are the center of the focus here.

Most importantly, namely, we find that a positive shock to government spending leads to a significant reduction in the markup $\mu_{t}$. The impact response is -0.27 , though the effect dies out fairly rapidly and markups return to normal within a few years. This central result has turned out to be robust to all variations that we investigated, like modest changes in the sample size, the number of countries covered, the choice of variables entering the panel VAR, and adding or deleting lags. Further robustness checks with respect to the postulated parameter values used to construct the markup series are presented in the following subsection. We are thus confident that fiscal expansions indeed tend to reduce price marginal cost markups.

This result is interesting in the light of recent debates surrounding the precise nature of the transmission process of government spending shocks. Hall (2009) argues that substantial output multipliers of government shocks can only be explained through countercyclical markup behavior. The reason is that with a constant markup, the additional labor input set forth by higher government spending through the usual wealth effect reduces the real wage due to decreasing returns to labor. This limits the amount of the equilibrium increase in labor. As a consequence, the output multiplier will be small, and likely too small to allow for an increase in consumption. If, on the other hand, the markup of price over marginal cost declines when a positive fiscal shock occurs, firms are willing to hire more labor at any given real wage rate, since the economy has effectively become more competitive. The resulting boost to labor demand limits the real wage decrease, or even allows for an increase in real wages, which may also give room to a positive response of consumption.

This theoretical argument is supported by the estimates presented in figure 1, which brings direct evidence that this line of reasoning seems to be consistent with empirical 
observations. Moreover, the substantial markup decline is well in line with the theoretical implications derived from the model of variable markups presented by Ravn et al. (2007). In their model, there is a non-price elastic component of goods demand, since consumers have consumption habits with respect to individual goods. An exogenous surge in fiscal spending then increases the relative importance of the price elastic component of demand, such that the overall price elasticity of demand rises and the markup declines. Ravn et al. (2007) estimate the parameters of their model by matching the theoretical impulse responses of their model to the empirical ones obtained from a four country panel VAR using government spending, output, consumption, the trade balance, and the real exchange rate as variables. They then show that their model, when evaluated using the estimated parameter values, implies that the markup ratio - which they treat as unobservable must decrease in response to a positive government shock. More specifically, they state that "in response to a one-percent increase in domestic government spending, markups in domestic markets fall by 26 basis points on impact" (p.21). Note that this theoretical implication of their model is very close to the empirical finding we present here. Our results thus can be seen as providing independent evidence for their view of the fiscal transmission mechanism, since the theoretically implied markup behavior of their model is empirically supported by our direct estimates of the markup ratios. Of course, this does not rule out that other theories that rely on countercyclical markup behavior in response to government shocks might be the root of the empirical results presented here.

\subsection{Robustness of the markup response}

Our finding that markups are conditionally countercyclical in response to government spending shocks depends, of course, on the validity of the procedure used to construct the unobservable markup series. In particular, we have postulated values for the elasticities that explain how the empirical markup measure follows from the observable time series on output, employment, capital, and real wages. Some of these parameters are controversial. In particular, the cost elasticity of the utilization rate $\psi$ is neither easy to pin down empirically, nor is there a standard calibration value used in the literature. Therefore, in this section we assess the robustness of the results with respect to different assumptions concerning parameters. In the next subsection, we analyze the behavior of the implied utilization rate series $u_{t}$ itself.

Figure 2 shows that the size of the initial markup response to a fiscal shock depends on the assumptions concerning the variability of capacity utilization. In particular, postulating a low elasticity $\psi$-implying low costs to varying utilization and therefore more volatile utilization- leads one to conclude a more muted markup response (see the dashed lines in 


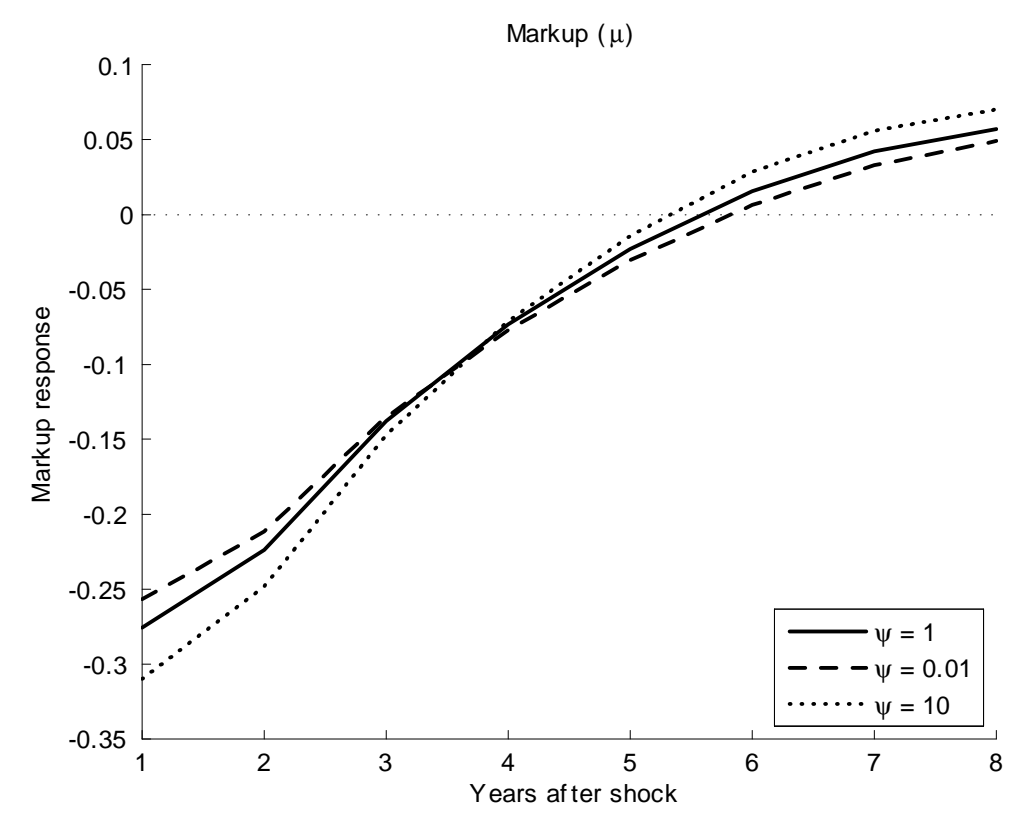

Figure 2: Markup responses for different elasticities of capacity utilization

figure 2), while the strongest markup response results if utilization is almost constant (see the dotted lines in figure 2). However, for all of these specifications, the markup response remains strongly negative, such that none of the qualitative conclusions depends on one's particular prior with respect to the parameter $\psi$. Models that do not take into account the variability of the utilization rate, like Monacelli and Perotti (2008), are therefore likely to overstate the amount to which the markup declines in response to a fiscal shock.

Next, figure 3 shows the markup response to a fiscal shock for different values of the elasticity of substitution $\sigma$ (keeping $\psi$ equal to its baseline value of one). For an elasticity of substitution closer to the Cobb-Douglas case of one (see the dotted line in the figure drawn for $\sigma=0.85)$ the markup response is more strongly negative. However, qualitatively, the result of a markedly negative response is unaltered even for the more realistic (in the short run) specification of a lower elasticity of substitution. Overall, these results suggest that a countercyclical markup response does not seem to be a figment of specific parameter choices, but appears to be a robust feature of the data for a wide range of plausible parameters.

\subsection{Utilization and hours}

Until now, we have concentrated on the markup response to fiscal shocks. However, while we argue that the markup is an important element in understanding the fiscal transmission process due to its impact on labor demand, it is also worthwhile to consider the supply 


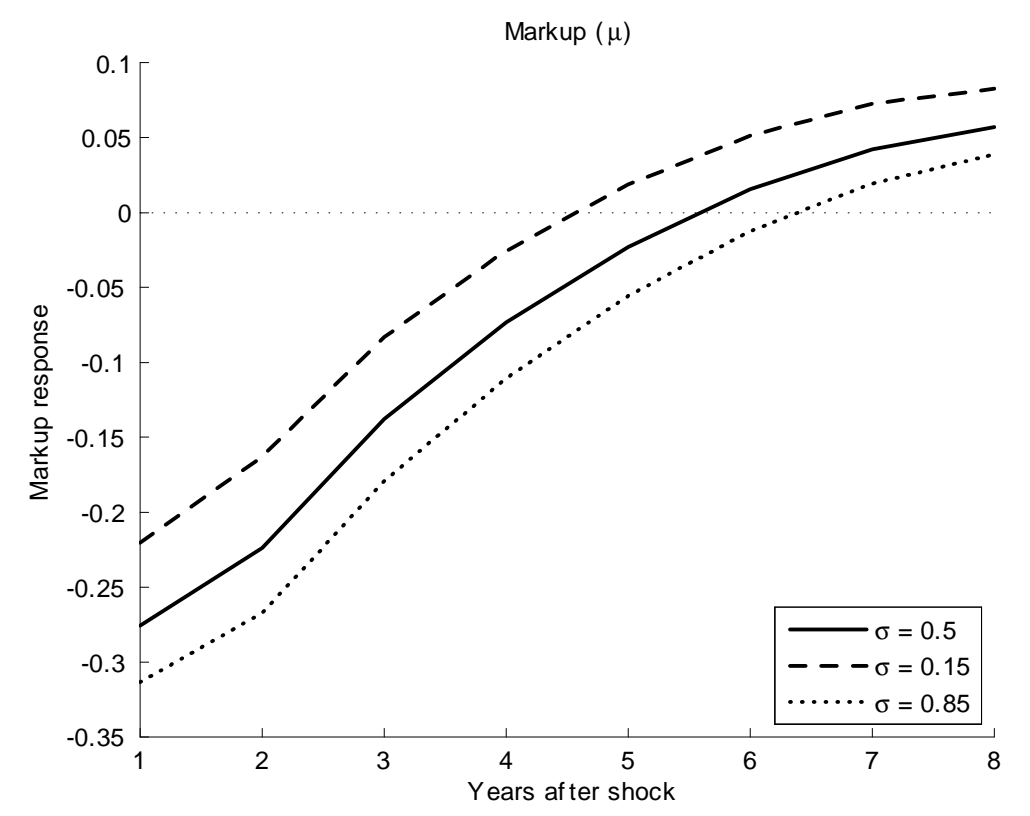

Figure 3: Markup responses for different elasticities of substitution in production

side responses in more detail. Therefore, we now add to the basic panel VAR - one at a time - total hours worked (in log-deviations from trend) and capacity utilization (as constructed in section 3). Figure 4 shows the responses of these variables to a one percent shock to government spending, using the baseline parameterization for the construction of the utilization rate series.

As can be seen in the left panel of figure 4, hours worked respond weakly and only initially positive (although neither the initial positive nor the later negative response is significant at the $90 \%$ confidence level). This result is somewhat surprising, at first sight because, as shown before and in a large previous literature, the output response is markedly positive. This raises the question how the additional output that follows a fiscal expansion is actually produced, given that capital is predetermined in the short run and labor input responds so weakly. Put differently, fiscal shocks seem to have a strongly positive short-run effect on labor productivity.

The likely explanation of this finding can be seen in the right panel of figure 4 , which shows the response of the utilization rate series that has been constructed along with the markup series. The utilization rate responds strongly positively to the government spending shock, with an impact effect about the same magnitude as the output response. This suggests that the positive output multiplier of fiscal shocks is to a large extent due to firms' responding by increasing capacity utilization, not labor input. Again, though not shown here, these results are qualitatively very robust to variations in parameters 
Figure 4: Impulse responses of hours worked and capacity utilization
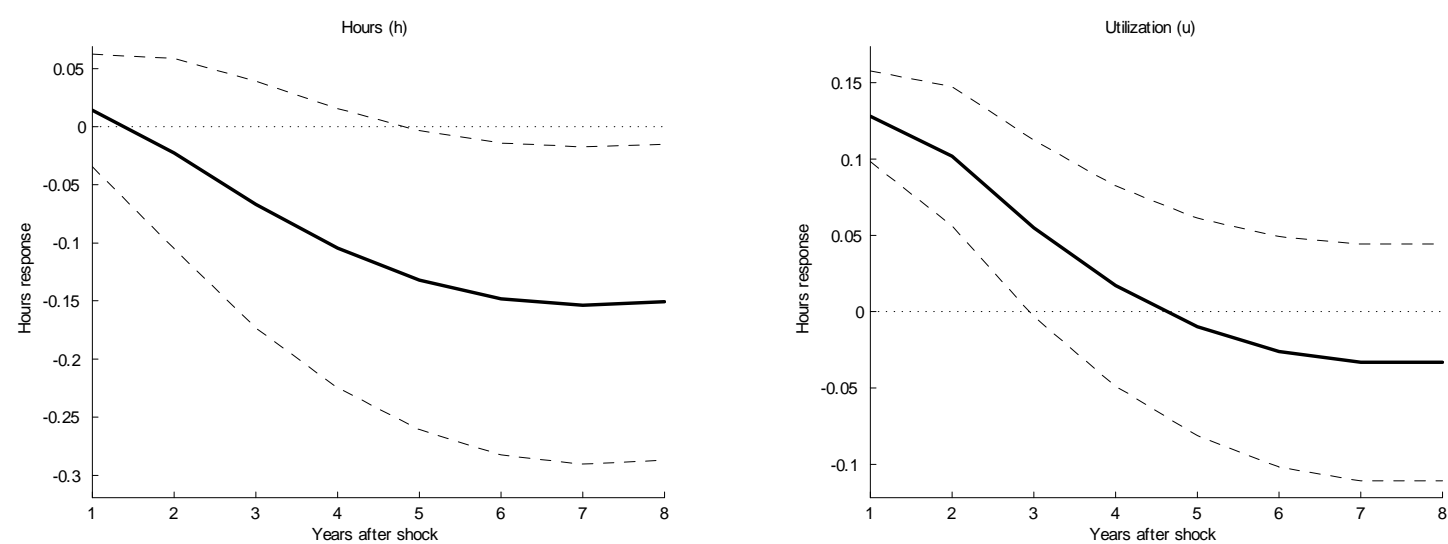

used. Note that while an hours response that is weaker than the output response is a typical finding in the earlier literature, this aspect of the effect of fiscal shocks has not been discussed much so far. Our finding thus suggests that cyclical capacity utilization is an important element in the fiscal transmission process.

Arguably, this also casts a different light on the discussion of the size of the government output multiplier from the point of view of stabilization policy. If countercyclical government spending is to be used to stabilize the economy, the effect on employment might well be negligible even if the output multiplier is substantial, since most of the output effect seems to come from increases in utilization.

\section{Conclusion}

The purpose of this paper has been to present direct evidence for the behavior of markups of price over marginal cost in response to government spending shocks. The reaction of the markup is important from a theoretical point of view, as several authors have argued that the available empirical evidence on the transmission of fiscal shocks can only be understood if the markup responds negatively to an increase in fiscal spending. It is thus natural to look for direct empirical evidence on markup changes following fiscal expansions.

Since the markup is not directly observable, the main empirical problem is to distinguish between changes in the markup and changes in the marginal product of labor due to cyclical fluctuations in the rate of unobservable capacity utilization rates and technical progress. This paper has used a method to jointly recover empirical measures for all three of these quantities from the loglinearized versions of optimizing first order conditions from a standard business cycle model with endogenous utilization and monopolistic competition. 
We have applied this methodology to a panel VAR with annual OECD country data and found that there is a strong and significant reduction in the markup ratio in response to an increase in government spending. The conditionally countercyclical markup response is qualitatively robust to variations in crucial parametric assumptions. This result lends empirical credibility to countercyclical markup theories of fiscal transmission. Furthermore, we also found that the response of hours worked to a government spending shock is surprisingly weak and hardly significant, if at all positive. While this casts doubt on the standard view of fiscal transmission, which explains a sizeably positive output response to higher public spending through the positive reaction of labor input, we suggest that the missing link appears to be a strongly positive reaction of capital utilization. Thus, a theoretical explanation of the transmission of shocks to government spending should account for the simultaneous negative reaction of markups and the positive reaction of factor utilization rates. The development of such a theoretical model that to our knowledge does not currently exist seems to be a fruitful field for further research.

\section{References}

Antras, P. (2004), Is the US aggregate production function Cobb-Douglas? New estimates of the elasticity of substitions, Contributions to Macroeconomics, vol 4, no. 1.

Barro, R.J., and C.J. Redlick (2009), Macroeconomic effects from government purchases and taxes, manuscript, Harvard University.

Basu, S. (1996), Procyclical productivity: increasing returns or cyclical utilization?, Quarterly Journal of Economics, 111, 719-51.

Basu, S., J.G. Fernald, and M. Kimball (2006), Are technology improvements contractionary?, American Economic Review, 96, 1418-1448.

Basu, S., and M. Kimball (1997), Cyclical productivity and unobserved input variation. NBER working paper \#5915.

Basu, S., and J.G. Fernald (1996), Returns to scale in U.S. production: estimates and implications, Journal of Political Economy, 105, 249-83.

Baxter, M., and D. Farr (2005), Variable capital utilization and international business cycles, Journal of International Economics, 65, 335-347.

Beetsma, R., M. Giuliodori, and F. Klaassen (2006), Trade spill-overs of fiscal policy in the European Union: a panel analysis, Economic Policy, 21, 639-687.

Beetsma, R., M. Giuliodori, and F. Klaassen (2008), The effects of public spending shocks on trade balances and budget deficits in the European Union, Journal of the Eu- 
ropean Economic Association, 6, 414-423.

Beetsma, R., M. Giuliodori, and F. Klaassen (2010), Temporal aggregation and SVAR identification, with an application to fiscal policy, Economics Letters, forthcoming.

Bilbiie, F.O. (2009), Non-separable preferences and Frisch labor supply: one solution to a fiscal policy puzzle, manuscript, HEC Paris Business School.

Blanchard, O.J., and R. Perotti (2002), An empirical characterization of the dynamic effects of changes in government spending and taxes on output, Quarterly Journal of Economics 177, 1329-1368.

Burnside, C., M. Eichenbaum, and S. Rebelo (1995), Capital utilization and returns to scale, NBER Working Paper No. 5125.

Chirinko, R.S. (2008), $\sigma$ : The long and short of it, Journal of Macroeconomics, 30, $671-86$.

Christiano, L.J., M. Eichenbaum, and C. Evans (2005), Nominal rigidities and the dynamic effects of a shock to monetary policy, Journal of Political Economy, 113, 1-45.

Corsetti, G., and G. Müller (2006), Twin deficits: squaring theory, evidence, and common sense, Economic Policy 21, 597-638.

Favero, C., and F. Giavazzi (2007), Debt and the effects of fiscal policy, NBER Working Paper No. 12822.

Gali, J., and M. Gertler (1999), Inflation dynamics: a structural econometric analysis, Journal of Monetary Economics, 44, 195-222.

Hall, R.E. (1991), Invariance properties of Solow's productivity residual, in: Peter Diamond (ed.), Growth, Productivity, Unemployment. Essays to celebrate Bob Solow's birthday, MIT Press: Cambridge etc., 71-112.

Hall, R.E. (2009), By how much does GDP rise if the government buys more output?, Brookings Papers on Economic Activity, forthcoming.

Hahn, J. and G. Kuersteiner (2002), Asymptotically Unbiased Inference for a Dynamic Panel Model with Fixed Effects when Both n and T Are Large, Econometrica, 70, 16391657.

Imbs ,J. (1999), Technology, growth, and the business cycle, Journal of Monetary Economics, 44.

Jaimovich, N., and S. Rebelo (2009), Can news about the future drive the business cycle?, American Economic Review, 99, 1097-1118.

Judson, R. A. and A. L. Owen (1999), Estimating dynamic panel data models: a guide for macroeconomists, Economics Letters, 65, 9-15.

Justiniano, A., G.E. Primiceri, and A. Tambalotti (2009), Investment shocks and business cycles, NBER Working Paper No. 15570. 
Juessen, F., and L. Linnemann (2010), Estimating Panel VARs from Macroeconomic Data: Some Monte Carlo Evidence and an Application to OECD Public Spending Shocks, mimeo.

Lütkepohl, H. (2006), New Introduction to Multiple Time Series Analysis, Springer, Berlin.

Monacelli, T., and R. Perotti (2008), Fiscal policy, wealth effects, and markups, NBER Working Paper No. 14584.

Nickell, S. J. (1981), Biases in Dynamic Models with Fixed Effects, Econometrica, 49, $1417-26$.

Pappa, E. (2009), The effects of fiscal expansions: an international comparison, manuscript, Universitat Autonoma de Barcelona.

Perotti, R. (2007), In search of the transmission mechanism of fiscal policy, NBER Macroeconomics Annual 22, 169 - 226.

Perotti, R. (2005), Estimating the effects of fiscal policy in OECD countries, CEPR Discussion Paper No. 4842.

Ravn, M., S. Schmitt-Grohe, and M. Uribe (2007), Explaining the effects of government spending shocks on consumption and the real exchange rate, NBER Working Paper No. 13328.

Rotemberg, J., and M. Woodford (1991), Markups and the business cycle, NBER Macroeconomics Annual, 63-129.

Rotemberg, J., and M. Woodford (1999), The cyclical behavior of prices and costs, in: Taylor, J.B., and M. Woodford (eds.), Handbook of Macroeconomics, North Holland, 1051-1135. 


\section{A Appendix}

\section{A.1 Data}

The countries included in the panel are all OECD countries for which all data were available for the period 1970 to 2008. These countries are Australia, Austria, Belgium, Canada, Denmark, Finland, France, Ireland, Italy, Japan, Luxembourg, the Netherlands, New Zealand, Norway, Portugal, Spain, Sweden, the United Kingdom, and the United States. Germany has been left out to avoid problems with structural breaks due to unification.

The data are taken from four sources: the European Union's Directorate General for Economics and Finance Annual Macroeconomic Database (AMECO), the Organization for Economic Cooperation and Development (OECD), the University of Groningen's Growth and Development Database (GGDC), and the International Monetary Fund (IMF). All data are retrieved from the respective publishing institutions' websites, with the exception of the IMF data, which are from the International Financial Statistics CD-ROM.

The (observable) variables entering the panel VARs are:

- $y_{t}$ : Real gdp per capita: Gross domestic product at 2000 market prices (AMECO), divided by total population (AMECO).

- $g_{t}$ : Real government spending per capita: Final consumption expenditure of general government at current prices (AMECO), divided by the price deflator of gdp (AMECO), and divided by total population (AMECO).

- $c_{t}$ : Real private consumption per capita: Private final consumption expenditure at 2000 prices (AMECO), divided by total population (AMECO).

- $d_{t}$ : Government debt to output ratio: mostly general government consolidated gross debt (percentage of gdp at market prices) (AMECO), exceptions see below.

- $R_{t}$ : Real interest rate: Long term government bond yields (IMF, International Financial Statistics, except for Finland and Spain. For these countries, the IMF data are missing and the long term interest rate from the OECD Main Economic Indicators was used instead), less growth rate of price deflator of gdp (AMECO).

For the construction of markups and utilization rates, we need data on real wages, hours worked, and the capital stock (and output $y_{t}$ ):

- $w_{t}$ : Real wage rate: Compensation of employees (AMECO), divided by the price deflator of gdp (AMECO), divided by total annual hours worked (GGDC). 
- $n_{t}$ : Hours: Total annual hours worked (GGDC).

- $k_{t}$ : Capital stock: Net capital stock at 2000 prices, total economy (AMECO).

For some countries for which AMECO data has not been available, the debt-to-output ratio has been taken from the OECD Economic Outlook Database 85, http://stats.oecd.org/ Index.aspx (general government gross financial liabilities, as a percentage of gdp). These countries are Canada, Norway, the Netherlands, and France. For Australia, the net debt as a percentage of gdp has been taken from the country's treasury website at http://www.budget.gov.au/2008-09/content/fbo/html/appendix_b.htm.

In some cases, minor data adjustments have been made: 1) the capital stock series for Australia and New Zealand lack entries for 2007 and 2008; the missing values were extrapolated by fitting and forecasting a quintic time trend to each series, 2) the Portuguese nominal interest rate is missing for 1974 and 1975; it has been interpolated linearly, 3) the Portuguese debt-to-output ratio is missing for 1973; the value for 1974 has been used instead , 4) the gross debt level (gross sovereign issued debt), and consequently the debtto-output ratio, for New Zealand has been taken directly from the country's treasury website; the observations for 1970 and 1971 were missing and were set to the value of 1973.

All results have been checked for robustness in the following sense: we arrive at the same conclusions as presented in the main text when we drop Australia, Luxembourg, Portugal, and New Zealand from the sample (which are the countries for which data adjustments have been made). The same holds if any single country out of these is excluded from the analysis.

\section{A.2 Construction of markup, utilization, and technology series}

The relevant theoretical restrictions are (3), the aggregate version of (4), as well as (5) and (6). These equations are repeated here for convenience:

$$
\begin{aligned}
r_{t} & =a^{\prime}\left(u_{t}\right)=\chi u_{t}^{\psi}, \\
y_{t} & =z_{t} F\left(u_{t} k_{t}, n_{t}\right), \\
z_{t} F_{2}\left(u_{t} k_{t}, n_{t}\right) & =\mu_{t} w_{t}, \\
z_{t} F_{1}\left(u_{t} k_{t}, n_{t}\right) & =\mu_{t} r_{t} .
\end{aligned}
$$

These are 4 equations in the 8 variables $r_{t}, k_{t}, u_{t}, \mu_{t}, n_{t}, y_{t}, w_{t}, z_{t}$. If we treat $n_{t}, k_{t}, y_{t}, w_{t}$ as observable and replace $r_{t}$ by (8) in (11), we can use these equations to empirically 
identify the unobservables $u_{t}, \mu_{t}, z_{t}$. We do so via a log-linear approximation. Following the method of Rotemberg and Woodford (1991, 1999), loglinearizing along a balanced growth path yields: (everything that does not carry a time index is a constant evaluated at the balanced growth path):

$$
\begin{aligned}
\widehat{r}_{t} & =\psi \widehat{u}_{t}, \\
\widehat{\mu}_{t}+\widehat{w}_{t} & =\widehat{F}_{2 t}+\widehat{z}_{t}, \\
\widehat{\mu}_{t}+\widehat{r}_{t} & =\widehat{F}_{1 t}+\widehat{z}_{t}, \\
\widehat{y}_{t} & =\widehat{F}_{t}+\widehat{z}_{t} .
\end{aligned}
$$

Note that

$$
\begin{aligned}
\widehat{F}_{t} & =\frac{F_{1} u k}{F}\left(\widehat{u}_{t}+\widehat{k}_{t}\right)+\frac{F_{2} n}{F} \widehat{n}_{t}+\widehat{z}_{t}, \\
\widehat{F}_{1 t} & =\frac{F_{11} u k}{F_{1}}\left(\widehat{u}_{t}+\widehat{k}_{t}\right)+\frac{F_{12} n}{F_{1}} \widehat{n}_{t} \\
\widehat{F}_{2 t} & =\frac{F_{21} u k}{F_{2}}\left(\widehat{u}_{t}+\widehat{k}_{t}\right)+\frac{F_{22} n}{F_{1}} \widehat{n}_{t} .
\end{aligned}
$$

From constant returns to scale in production we have for the elasticities

$$
\begin{aligned}
F_{12} n & =-F_{11} u k, \\
F_{12} u k & =-F_{22} n,
\end{aligned}
$$

such that

$$
\begin{aligned}
& \widehat{F_{1 t}}=\frac{F_{12} n}{F_{1}}\left(\widehat{n}_{t}-\widehat{u}_{t}-\widehat{k}_{t}\right), \\
& \widehat{F}_{2 t}=\frac{F_{12} u k}{F_{2}}\left(\widehat{u}_{t}+\widehat{k}_{t}-\widehat{n}_{t}\right) .
\end{aligned}
$$

Further note that constant returns implies for the elasticity of substitution $\sigma$ :

$$
\frac{1}{\sigma}=\frac{F F_{12}}{F_{1} F_{2}}
$$

Therefore, the elasticities needed above are

$$
\begin{aligned}
\frac{F_{12} n}{F_{1}} & =\frac{1}{\sigma} \frac{F_{2} n}{F} \\
\frac{F_{12} u k}{F_{2}} & =\frac{1}{\sigma} \frac{F_{1} u k}{F} .
\end{aligned}
$$


Further, we know that

$$
\begin{aligned}
\mu w & =F_{2} z \Rightarrow \frac{F_{2} n}{F}=\mu \frac{w n}{y}=\mu s_{L}, \\
\mu r & =F_{1} z \Rightarrow \frac{F_{1} u k}{F}=\mu \frac{r u k}{y}=\mu s_{K},
\end{aligned}
$$

where $s_{L}$ and $s_{K}$ are the constant shares of labor and capital income in production along the balanced growth path, respectively.

Thus, we finally have

$$
\begin{aligned}
\widehat{r}_{t} & =\psi \widehat{u}_{t} \\
\widehat{\mu}_{t}+\widehat{w}_{t} & =\frac{\mu s_{K}}{\sigma}\left(\widehat{u}_{t}+\widehat{k}_{t}-\widehat{n}_{t}\right)+\widehat{z}_{t} \\
\widehat{\mu}_{t}+\widehat{r}_{t} & =\frac{\mu s_{L}}{\sigma}\left(\widehat{n}_{t}-\widehat{u}_{t}-\widehat{k}_{t}\right)+\widehat{z}_{t} \\
\widehat{y}_{t} & =\mu s_{K}\left(\widehat{u}_{t}+\widehat{k}_{t}\right)+\mu s_{L} \widehat{n}_{t}+\widehat{z}_{t}
\end{aligned}
$$

Writing the above in matrix form and substituting out $\widehat{r}_{t}=\psi \widehat{u}_{t}$ gives

$$
\left(\begin{array}{c}
\widehat{u}_{t} \\
\widehat{\mu}_{t} \\
\widehat{z}_{t}
\end{array}\right)=\left(\begin{array}{ccc}
-\frac{\mu s_{K}}{\sigma} & 1 & -1 \\
\frac{\mu s_{L}}{\sigma}+\psi & 1 & -1 \\
\mu s_{K} & 0 & 1
\end{array}\right) \quad\left(\begin{array}{cccc}
0 & -\frac{\mu s_{K}}{\sigma} & \frac{\mu s_{K}}{\sigma} & -1 \\
0 & \frac{\mu s_{L}}{\sigma} & -\frac{\mu s_{L}}{\sigma} & 0 \\
1 & -\mu s_{L} & -\mu s_{K} & 0
\end{array}\right)\left(\begin{array}{c}
\widehat{y}_{t} \\
\widehat{n}_{t} \\
\widehat{k}_{t} \\
\widehat{w}_{t}
\end{array}\right)
$$

which is equation (7) in the main text.

Thus, given a vector of the period $t$ observations on $\widehat{y}_{t}, \widehat{n}_{t}, \widehat{k}_{t}, \widehat{w}_{t}$, we can infer the period $t$ values of the unobservables $\widehat{u}_{t}, \widehat{\mu}_{t}, \widehat{z}_{t}$ if we choose values for the steady state elasticities: $\mu, \sigma, \psi, s_{L}$, and $s_{K}=\left(1-\mu s_{L}\right) / \mu$. For the empirical work, we interpret the hatted observable variables $\widehat{y}_{t}, \widehat{n}_{t}, \widehat{k}_{t}, \widehat{w}_{t}$ as log-deviations from deterministic time trends, such that for any variable $\widehat{x}_{t}=\ln \left(x_{t} / x\right)$. The levels of the variables can be recovered as $x_{t}=\exp \left(\widehat{x}_{t}\right) / x$. The constant steady state levels needed to perform these calculations are chosen as discussed in the main text. 


\section{A.3 Markup series}

The next two figures display the markup series $\mu_{t}$ obtained using the approach outlined in Section A.2, for the benchmark parameter set $\sigma=0.5$ and $\psi=1$. Note that while the level of the average markup is imposed a priori, the fluctuations visible in the figures are not.

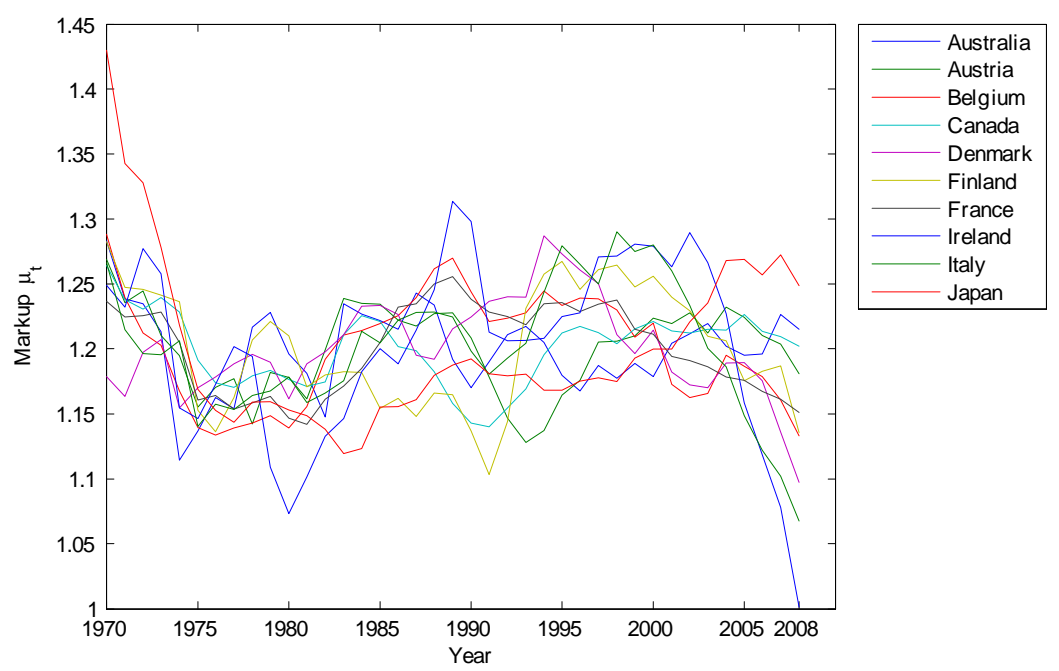

Figure 5: Markup series for the benchmark parameter set, part I

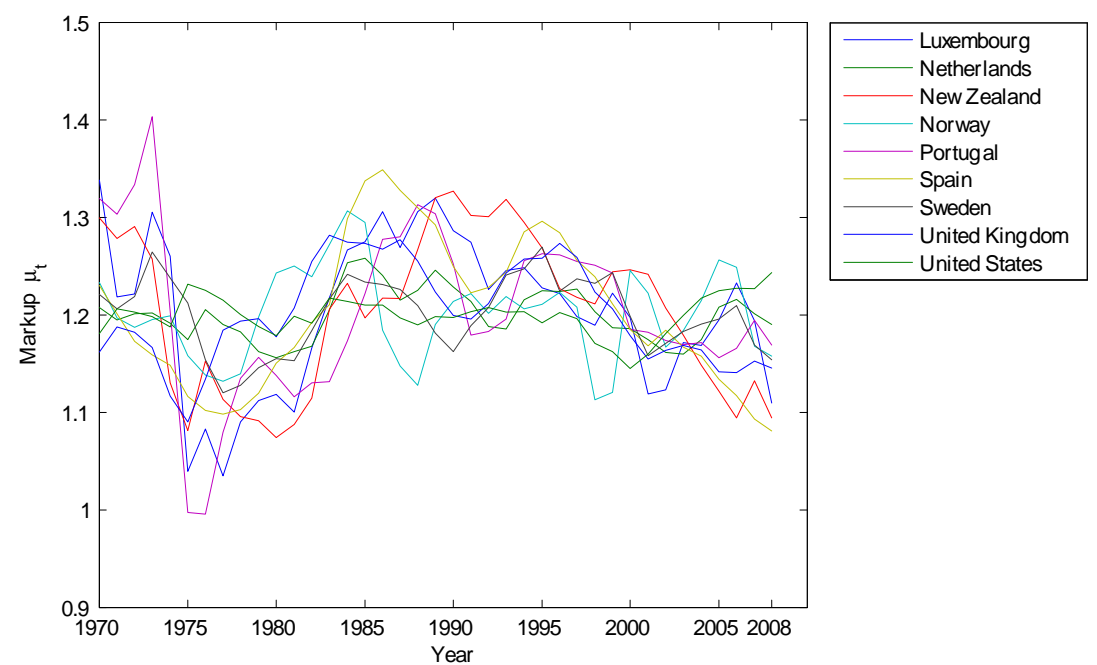

Figure 6: Markup series for the benchmark parameter set, part II 


\section{A.4 Comparison of different estimation techniques for the panel VAR}

Figure 7 displays the impulse resonse functions to a one percent shock to government spending obtained using the bias-corrected fixed effects estimator developed by Hahn and Kuersteiner (2002) (solid lines; these are the same results as displayed in figure 1) and the corresponding results obtained using the simple fixed effects estimator (solid lines marked with an asterisk).
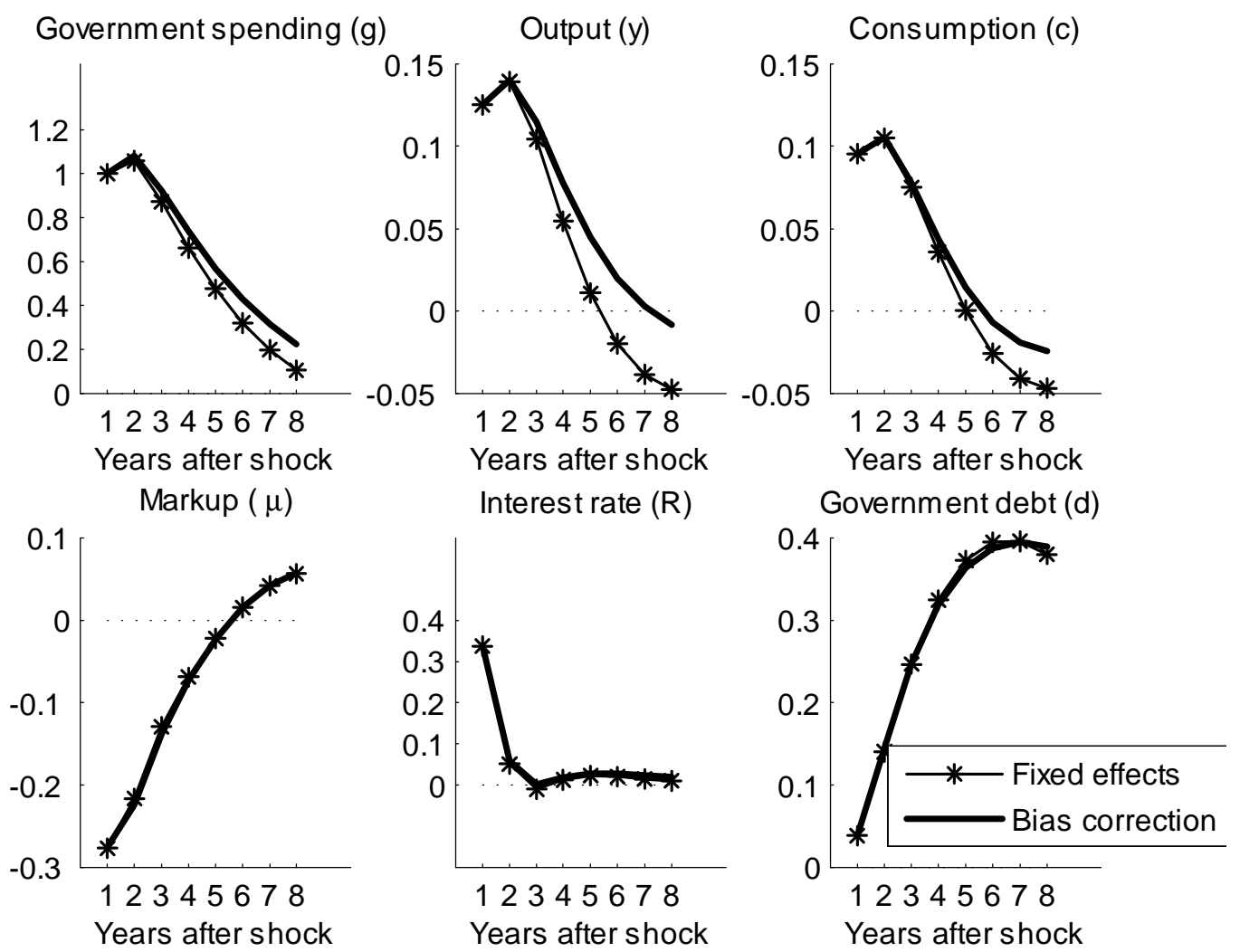

Figure 7: Comparison of IRFs obtained using the simple fixed effects estimator and the bias-corrected fixed effects estimator developed by Hahn and Kuersteiner (2002). 


